\title{
Pentosan Polysulfate as a Disease Modifier of Cartilage Degeneration in Experimental Osteoarthritis
}

\author{
Ahmed M Elmesiry ${ }^{1 *}$, Magdi A Seleim², Ali A Mansour ${ }^{3}$ and David Cullis-Hill ${ }^{4}$ \\ ${ }^{1}$ Diagnostic Imaging and Endoscopy, Animal Reproduction Research Institute, Agriculture Research Center, 12556 Haram, Giza, Egypt \\ ${ }^{2}$ Department of Surgery, Kafrelsheikh University, 33156 Kafrelsheikh, Egypt \\ ${ }^{3}$ Department of Anatomy, Kafrelsheikh University, 33156 Kafrelsheikh, Egypt \\ ${ }^{4}$ Sylvan Scientific Pty Ltd, 111 Bronte Rd, Bondi Junction, Sydney, NSW 2022, Australia
}

\begin{abstract}
Reasons for performing study: Disease modifying drugs for Osteoarthritis $(O A)$ is an important trend of development of an appropriate therapeutic protocol for both human and animal. To date no ideal OA treatment protocol has been described.
\end{abstract}

Objectives: To assess clinical, histologic, and biochemical effects of sodium pentosan polysulfate (NaPPS) administered intramuscullary (IM) for treatment of experimentally induced osteoarthritis in donkeys.

Study design: OA was induced using repeated injection of allogenous donkey cartilage. Six donkeys received NaPPS (3 mg/kg, IM) on study days $70,77,84$, and 91 . Six control donkeys received the same volume of saline $(0.9 \% \mathrm{w} / \mathrm{v} \mathrm{NaCl}) \mathrm{IM}$ on study days $70,77,84$, and 91 . Clinical, gross, histologic, histochemical, and biochemical findings as well as synovial fluid analysis were evaluated.

Methods of testing hypotheses: Lameness score, carpal circumference, joint flexion angle, Synovial fluid analysis, light and scanning electron microscopy were evaluated.

Results: Induction of osteoarthritis caused increase in the lameness score, joint circumference, synovial fluid calcium, phosphorus, magnesium, total protein and leukocyte count and cartilage damage. NaPPS treatment significantly reduced synovial fluid $\mathrm{Ca}, \mathrm{Mg}, \mathrm{P}$ and cartilage damage.

Conclusions: NaPPS resulted in significant improvement in clinical signs and articular cartilage healing, and no adverse effects were detected confirming that NaPPS has disease-modifying properties.

Potential relevance: NaPPS is a suitable therapeutic option for osteoarthritis in equines.

Keywords: Pentosan polysulfate; Osteoarthritis; Cartilage; Synovial fluid; Joint crystals; ACP model

\section{Introduction}

Equine osteoarthritis (OA) maybe considered as a group of disorders characterized by a common end stage: progressive deterioration of the articular cartilage accompanied by changes in the bone and soft tissues of the joint. The deterioration of the articular cartilage is characterized by local splitting and fragmentation (fibrillation) of articular cartilage. Synovitis and joint effusion are often associated with the disease, and, clinically, the disease is characterized by pain and dysfunction of the affected joint [1]. Several epidemiologic studies have found that lameness due to joint disease is the most significant factor responsible for inability to race and loss of performance [2-4].

Drugs used to treat osteoarthritis can be considered as modifying the clinical signs of osteoarthritis or as modifying the disease itself. In general, the former alleviate pain and inflammation and lead to a positive clinical outcome but may not affect the progression of the underlying disease process. The latter slow or reverse the disease process but may not have any direct effect on the clinical signs of the disease. The optimal medication for osteoarthritis would be a drug that provides both effects in a safe and convenient manner.

Various medications have been evaluated or used for treatment of horses with osteoarthritis, including nonsteroidal anti-inflammatory drugs (NSAIDs), corticosteroids, polysulfates glycosaminoglycans (PSGAG), and hyaluronan [5].
Although NaPPS has been used in Europe for more than 30 years as an antithrombotic / antilipidemic agent, its potential as a diseasemodifying antiarthritic agent has been realized more recently [6,7]. The backbone of PPS, which consists of repeating units of (1-4)-linked $\beta$-Dxylano-pyranoses, is isolated from beech-wood hemicellulose.

The possible mechanism of action of PPS are improving of the nutritional supply to the joint, increasing of biosynthesis of extracellular matrix, inhibiting proteinases activity, enhancing TIMP-3 level in cartilage and Inhibiting of inflammatory activities of IL-1 and TNFa [6].

There are numbers of clinical trials reported the use of PPS in dog [8-12], sheep [13] and human [14-16].

The pharmacology of PPS has been described in the horse $[17,18]$ and its use for equine joint disease has been reported [19], but results

*Corresponding author: Ahmed M Elmesiry, Researcher, Animal Reproduction Research Institute Diagnostic Imaging and Endoscopy, 5 El-Aharam Garden st, AlHaram, Giza 12556, Egypt, Tel: +201062099431; E-mail: elmesiry@outlook.com

Received May 03, 2016; Accepted May 20, 2016; Published May 31, 2016

Citation: Elmesiry AM, Seleim MA, Mansour AA, Hill DC (2016) Pentosan Polysulfate as a Disease Modifier of Cartilage Degeneration in Experimental Osteoarthritis. J Arthritis 5: 199. doi:10.4172/2167-7921.1000199

Copyright: (c) 2016 Elmesiry AM, et al. This is an open-access article distributed under the terms of the Creative Commons Attribution License, which permits unrestricted use, distribution, and reproduction in any medium, provided the original author and source are credited. 
from the later study needs further investigation in another controlled animal model.

The allogenous cartilage particle (ACP) model was used to induce osteoarthritis in dogs [20], rabbits [21], horses [22] and donkeys [23]. Its benefits has been described recently as an in vivo model for crystal associated osteoarthritis [24].

The purpose of the study reported here was to evaluate the effects of NaPPS, administered IM, in experimentally-induced osteoarthritis by evaluation of clinical (joint lameness, range of motion, response to flexion, and synovial effusion), radiographic, gross, macroscopic, histologic, and biochemical outcome measures. Our hypothesis was that the outcome of donkeys treated with PPS would be more favorable than that of control donkeys.

\section{Material and Methods}

The experiment was approved by the Committee on Animal Experimentation at the Kafrelsheikh University, Egypt (Protocol no. VET1789 - 1/4/2013).

\section{Donkeys}

The present study was performed with 13 healthy Egyptian local breed male donkeys weighting from 150 to $200 \mathrm{~kg}$. Animals were housed in indoor stalls and fed on a maintenance ration of mixed grain with hay and unlimited water. All donkeys were dewormed with ivermectine $200 \mathrm{mcg} / \mathrm{kg}$ body weight (Eqvalan; Merial Limited. USA)

Prior to inclusion in the study, lameness examination, body condition, radiographs of carpal joints, range of motion of carpal joints (angle of flexion) and evidence of joint effusion were assessed to ensure that all previous variables were within normal limits (baseline measurement).

Donkeys were allowed to acclimatize for 2 weeks prior to the study. During the acclimatization period, the donkeys were trained daily to familiarize them to the experimental conditions (investigators, environment, handling and vein puncture).

\section{Cartilage powder preparation}

One local breed donkey weighting $\pm 150 \mathrm{~kg}$ was euthanized, and the articular cartilage was removed from the shoulder, carpal, fetlock, pastern, hock and stifle joints in a biosafety cabinet under aseptic conditions. The pooled cartilage was powdered under liquid nitrogen in a mortar, producing particles as small as $20 \mathrm{~mm}$ in diameter (able to pass easy through a 14-gauge needle). These particles were resuspended at a concentration of $50 \mathrm{mg} / \mathrm{ml}$ in a physiological saline solution contained amikacin sulfate $(50 \mathrm{mg} / \mathrm{ml}$ ) (Amikin; BristolMyers Squibb). An aliquot of the suspension was cultured for 72 hour on ordinary media to confirm sterility. The cartilage stock solution was stored on a fridge $\left(4^{\circ} \mathrm{C}\right)$ until use $[23,24]$.

\section{Study design}

At day 0 , the remaining 12 donkeys were sedated with Xylazine $\mathrm{HCL}$ in a dose of $1 \mathrm{mg} / \mathrm{kg}$ (Rompun; Bayer animal health). The skin was aseptically prepared for arthrocentesis of each right radiocarpal joint to obtain synovial sample for baseline analysis. All donkeys were received $100 \mathrm{mg}(2 \mathrm{~mL})$, intra-articularly into the right radiocarpal joint using a $14 \mathrm{G}$ needle. These injections were repeated at 7,14,21,28,35,42 and 56 days. The left radiocarpal joint were injected with the same solution without cartilage particles (sham injection) and served as non-arthritis controls. Donkeys were trotted for $15 \mathrm{~min} /$ day on soft ground 5 days each week until the begin of the treatment.

At day 70, the 12 donkeys were divided in to two equal groups of six. Group A (PPS group) received NaPPS $3 \mathrm{mg} / \mathrm{kg}$ (Cartrophen Equine Forte; Biopharm Australia), IM, 4 doses at days 70, 77, 84 and 91. Group B received the same volume of saline $(0.9 \% \mathrm{Na} \mathrm{Cl}) \mathrm{IM}$ at the same time points (Control group).

All animals had box rest for 2 weeks then had another 2 weeks of of being walked by lead ( 20 min daily). All donkeys were euthanized at day 119 (Figure 1).

\section{Outcome measures}

Clinical examination: Clinical examinations of both right and left forelimbs were performed weekly from day 0 (baseline) throughout the study period. A professor of large animal surgery (Lameness specialist) assessed all clinical outcome variables blinded to the treatment assignment.

Lameness score: The right and left forelimb of the 12 donkeys were evaluated for lameness score on a scale 0 to 5 according to American Association of Equine Practitioners (AAEP) grading system (0: Lameness not perceptible under any circumstances, 1:Lameness is difficult to observe and is not consistently apparent, regardless of circumstances, 2:Lameness is consistently apparent under certain circumstances, 3: Lameness is consistently observable at a trot under all circumstances, 4: Lameness is obvious at a walk. 5:Lameness produces minimal weight bearing in motion) [25].

Circumference of the carpal joint: Measurements obtained at the proximal aspect of the carpus by using of a measurement tape (in $\mathrm{cm}$ ),

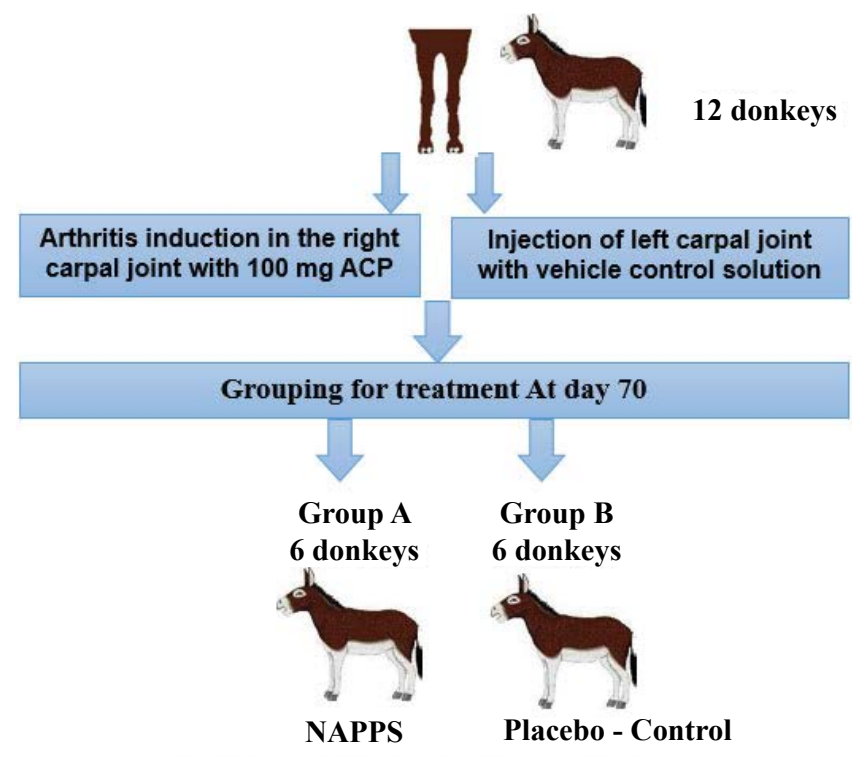

Weekly single IM injection for 4 weeks

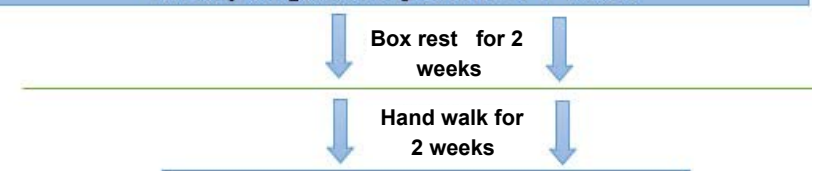

Euthanasia for group A \& B at day 119

Figure 1: Flowchart of the study protocol. 
and with the aid of the anatomical reference points (accessory, radial, ulnar and intermediate carpal bones). Circumference was obtained weekly; hair over the selected area was clipped on a regularly scheduled basis [26].

Maximum carpal flexion angle: Maximum carpal flexion was measured weekly by slowly flexing the carpus until the donkey resisted. The angle was then measured in degrees with Goniometer [26].

Synovial fluid analysis: Synovial fluid sample (1 to $2 \mathrm{~mL})$ was aseptically aspirated from each joint before each injection. The conventional analysis of synovial fluid included assessment of total protein, Calcium, Phosphorus, Magnesium concentration and white blood cell (WBC) count [27]. Total protein concentrations, Calcium, Phosphorous and Magnesium were determined via Double Beam UV Visible Spectrophotometer and commercial kits however, the WBC was counted using an automated cell counter. A clinical pathologist who was blinded to the treatment protocol did the synovial analyses [24,27].

Gross pathology: Animals were euthanized by administration of pentobarbitone sodium (100 mg/kg IV) (Lundbeck Inc.). Both articular surfaces were photographed, directly perpendicularly, from a standard distance of $10 \mathrm{~cm}$ with a digital camera (Sony Cybershot DSC-W350) and the photographs were edited with a photo editing software (Adobe Photoshop CS2) in order to outline both the osteoarthritic lesions and the total articular surface. Tissue samples collected from joint capsule and articular cartilage (Figure 1). The right and left carpal joints specifically examined for degree and location of articular cartilage fibrillation or erosion. A subjective grade (scale of 0 to 4) assigned for partial- and full-thickness cartilage erosion as well as synovial membrane hemorrhage. A total erosion score assigned, also with a scale of 0 to 4 . For each of the 2 variables, grade 0 represented no pathological change and 4 represented a severe change. Each joint also assessed for the presence of synovial adhesions [28].

Light microscopy: Specimens from the synovial membrane and joint capsule harvested and placed in neutral-buffered $10 \%$ formalin (NBF) stained with $\mathrm{H} \& \mathrm{E}$ and examined microscopically. Samples evaluated for cellular infiltration, synovial intimal hyperplasia, subintimal edema, subintimal fibrosis and subintimal vascularity. Each variable was graded and reported as a numeric value 0 to $4(0=$ normal, $1=$ slight change, $2=$ mild change, $3=$ moderate change, and $4=$ severe change [28].

Full thickness articular cartilage samples of $5-\mathrm{mm}^{2}$ diameter were obtained from each joint (Figure 2). Sampling sites were chosen to represent an area of dorsal cartilage $(\mathrm{C} 1$ and $\mathrm{C} 3)$ and palmar cartilage (C2 and C4). Samples were placed in (NBF) for 7 days then in $10 \%$ $(\mathrm{w} / \mathrm{v})$ EDTA for 21 days for decalcification then processed routinely to paraffin wax for histological examination by a professor of pathology blinded to treatment assignment. Samples were sliced into $5-\mu \mathrm{m}$ sections and stained with $\mathrm{H} \& \mathrm{E}$, cartilage were graded on a scale of 0 to 6 (Grade 0: Smooth, Grade 1: Surface irregular, Grade 2: Surface discontinuous, Grade 3: Vertical fissure, Grade 4: Erosion, Grade 5: Denudation, Grade 6: Deformation) [29].

Scanning electron microscopy: Cartilage C2 and C4 pieces obtained from the distal redial surface of each right carpal joint were fixed in $2.5 \%(\mathrm{v} / \mathrm{v})$ glutaraldehyde solution in phosphate buffer saline (PBS pH 7.4) for approximately $24 \mathrm{~h}$, followed by thorough washing using multiple changes of PBS. Secondary fixation was in a solution of $1 \%(\mathrm{w} / \mathrm{v}$ ) osmium tetroxide in PBS for $1.5 \mathrm{~h}$. Specimens were again rinsed in multiple changes of PBS then dehydrated with an ascending ethanol series $50 \%, 60 \%, 70 \%, 80 \%, 90 \%, 100 \%$, followed by pure, dry acetone. This was followed immediately by critical point drying with liquid carbon dioxide, coating with gold and examination by a professor of pathology using a JEOL JSM 5200LV electron microscope. Cartilage surface was examined for erosion and micro cracks [30] and synovial membrane was examined for synovial villi destruction. Variable was graded and reported as a numeric value 0 to $4(0=$ normal, $1=$ slight change, $2=$ mild change, $3=$ moderate change, and $4=$ severe change [24].

Statistical analysis: Variables including carpal flexion angel, carpal circumference, TP and TWBC analyzed using a repeated measures analysis of variance (ANOVA) model with IBM SPSS (Version 23). Any test with a $\mathrm{P}$ value $<0.05$ was declared statistically significant. When individual comparisons were made, Bonferroni post hoc test was used and $\mathrm{P}<0.05$ was considered significant. The Kruskal-Wallis non-parametric ANOVA was used to evaluate statistical differences in lameness score, gross pathological and histo-pathologic scores. Values are reported as mean \pm standard deviations.

\section{Results}

\section{Clinical examination}

Lameness score: There was an increase in the in lameness scores of the right forelimb in all donkeys at day $70(1.67 \pm 0.47)$. In PPS group, lameness begin to decrease from day $77(1 \pm 0)$ till return to the base line at day 105. However in control group, the score begin to decrease at day $112(1 \pm 0)$ but did not return to its baseline analysis (Figure $3 \mathrm{~A}$ ). There was a significant difference between the right forelimb of control and PPS-treated groups at study day 77, 84, 91,98 and $105(\mathrm{P}<0.001)$.

Carpal circumference: Carpal circumference was increased in right forelimb of all donkeys at day $70(24.2 \pm 0.5)$. Then begin to decrease at day 77 in PPS Group $(23.7 \pm 0.7)$ and at day 98 for control group $(24.3 \pm 0.7)$. At the end of the study, the circumference did not return to its baseline in right forelimb of both groups (Figure 3B). There was no significant differences between the two groups at the end of the study $(\mathrm{P}=0.126)$.

Maximum carpal flexion angle: The flexion angle decreased in the right forelimb of both group at day $70(150 \pm 4)$ for PPS group and (148 \pm 3 ) for control group. The angle began to increase in day 77 in PPS group $(155 \pm 4)$ and in day 91 in control group $(149 \pm 3)$. At the end of the study the angle return to its baseline analysis in PPS group and control group (Figure 3C). There was a significant difference between PPS and control group at study day 77, 84, 91,98 and $105(\mathrm{P}<0.05)$.

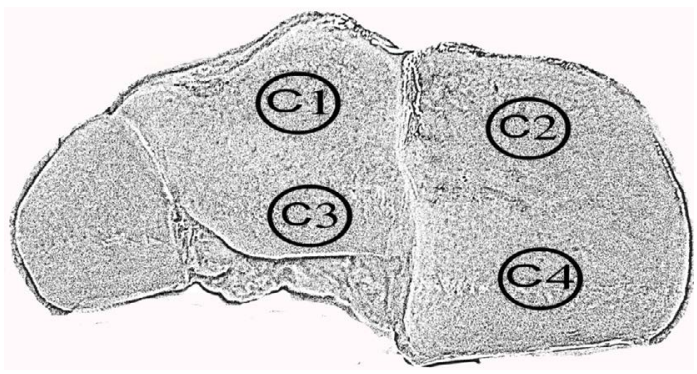

Figure 2: Illustration of cartilage collection sites from distal articular surface of the radius. $\mathrm{C} 1$ and $\mathrm{C} 3$ represented samples for the Light microscopy while C2 and C4 for the SEM. 

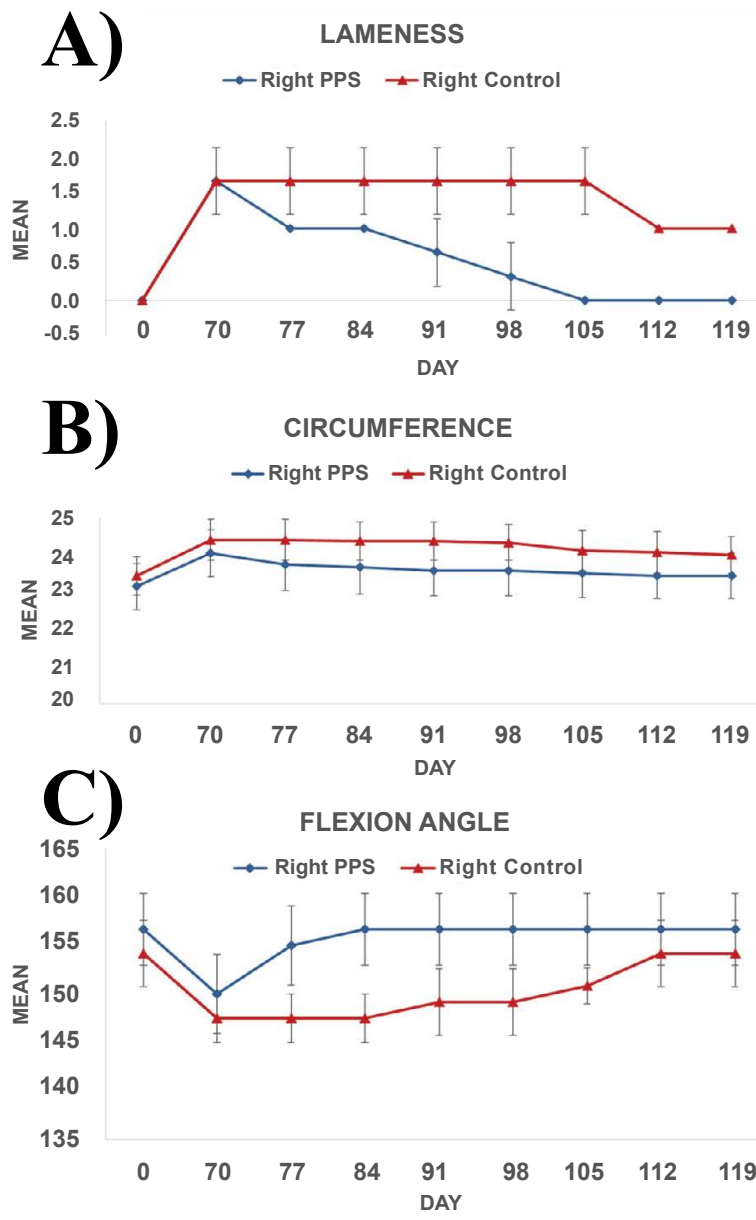

Figure 3: A) - Mean lameness score over the study period. B) - Mean carpal circumference over the study period. C) - Mean carpal flexion angle over the study period.

Synovial fluid analysis: Synovial WBCs count was increased in PPS group ( $400 \pm 81$ cells $/ \mu \mathrm{L}$ ) and control group (433 \pm 74 cells/ $\mu \mathrm{L}$ at day 70 throughout the study but with no significant differences between the two groups.

Total protein also increased in PPS group $(3 \pm 0.1 \mathrm{~g} / \mathrm{dL})$ and control group $(2.9 \pm 0.1 \mathrm{~g} / \mathrm{dL})$, at day 70 throughout the study but with no significant differences between the two groups.

Calcium (Ca) level was significantly increased from day 35 in PPS group (2.7 \pm 0.4$)$ and control group (2. \pm 0.2$)$ reaching its maximum level at day 70 in PPS group $(3 \pm 0.3)$ and control group $(3.3 \pm 0.3)$. calcium level begin to decreased at day 77 in PPS group (2.9 \pm 0.3$)$ and control group $(3.2 \pm 0.3)$ and continued to decease till the end of the study reaching $2.5 \pm 0.3$ in PPS group and $2.7 \pm 0.2$ in control group. There was no significant difference between the right forelimb of both group at any study day $(\mathrm{P}>0.05)$ (Figure $4 \mathrm{~A})$. Phosphorus $(\mathrm{P})$ level was significantly increased from at day 28 in PPS group (10.9 \pm 0.7$)$ and control group $(11.5 \pm 0.5)$ reaching its maximum level at day 70 in PPS group $(12.3 \pm 0.6)$ then begin to decrease at day $77(11.7 \pm 0.7)$ till the end of the study $(10.5 \pm 0.9)$. However, in the control group phosphorus continued to increase to the end of the study $(31.9 \pm 2.66)$. There was a significant difference between the right forelimb of both group from day 77 to the end of the study $(\mathrm{P}<0.05)$ (Figure 4B). Magnesium $(\mathrm{mg})$ level was significantly increased at day 21 in PPS group $(2.3 \pm 0.3)$ and at day 14 in control group $(2.5 \pm 0.4)$ reaching its maximum level at day 70 in PPS group $(3.9 \pm 0.3)$ then begin to decrease at day 77 (3.8 \pm $0.3)$ till the end of the study $(2.3 \pm 0.4)$. However, in the control group magnesium continued to increase to the end of the study $(6.5 \pm 0.6)$. There was a significant difference between the right forelimb of both group from day 77 to the end of the study $(\mathrm{P}<0.05)$ (Figure $4 \mathrm{C})$.

Gross pathology: The right joints of both groups had high cartilage erosion score (PPS group $3.33 \pm 0.47$; control group $4 \pm 0$ ) compared to the left one $(0 \pm 0)$. In PPS group most of the lesions are limited to $\mathrm{C} 3$ region however $\mathrm{C} 1$ and $\mathrm{C} 3$ characterized by fibrous like membrane (Figure 5A). In control group partial and full thickness cartilage erosion distributed all over the joint region (Figures $5 \mathrm{~B}$ and $5 \mathrm{C}$ ). There was no significant difference between the two groups $(\mathrm{P}=0.138)$. Synovial membrane haemorrhage improved in right PPS joints $(0.67 \pm 0.47)$ compared to the right control $(2.67 \pm 0.47)$. There was a significant difference between the right joints in both groups $(\mathrm{P}=0.003)$.

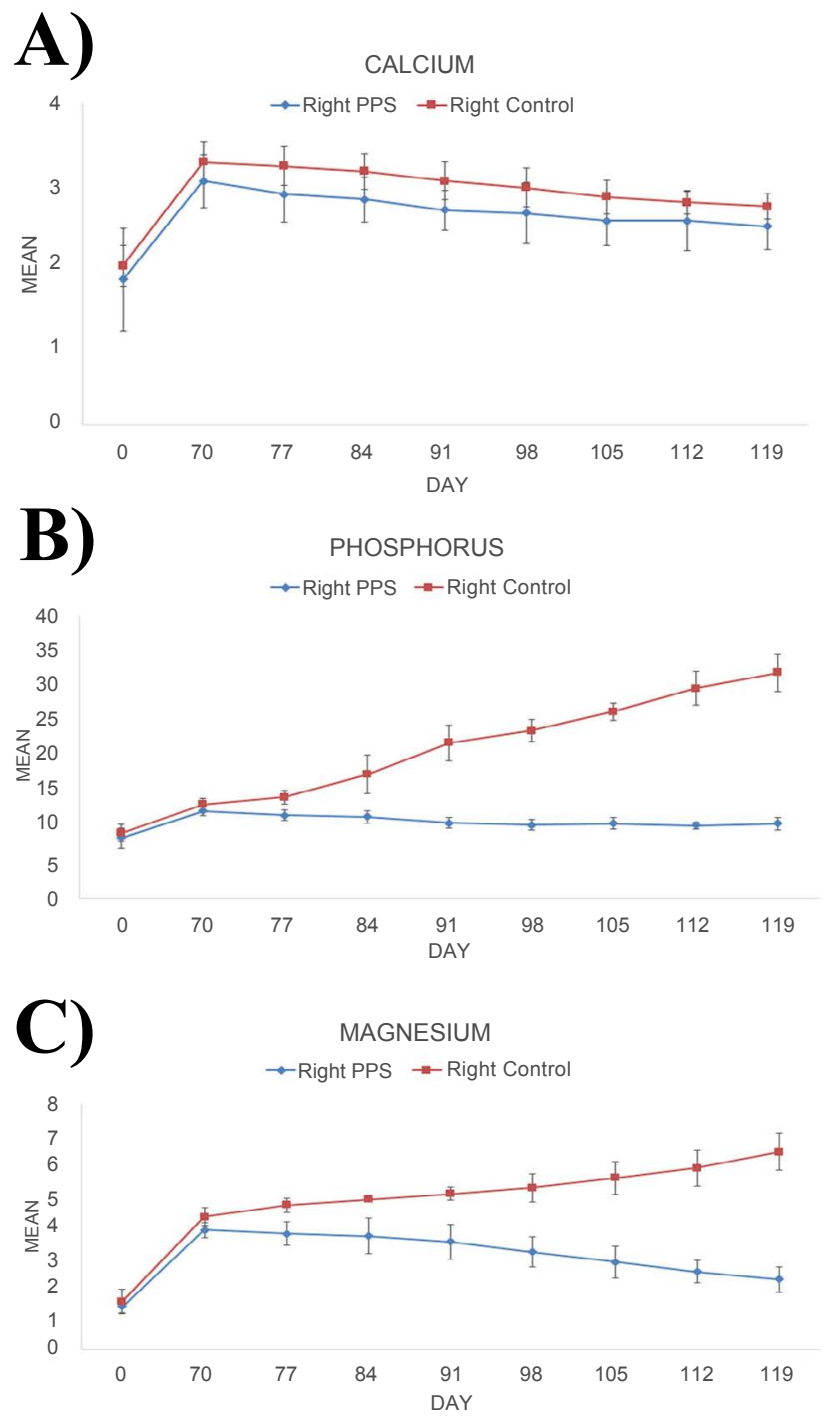

Figure 4: A) - Mean synovial fluid calcium over the study period. B) - Mean synovial fluid phosphorus over the study period. C) - Mean synovial fluid magnesium over the study period. 


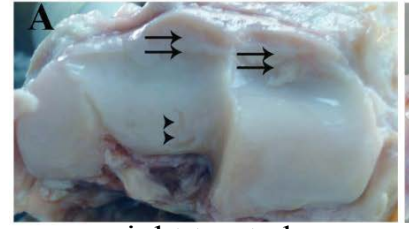

right treated

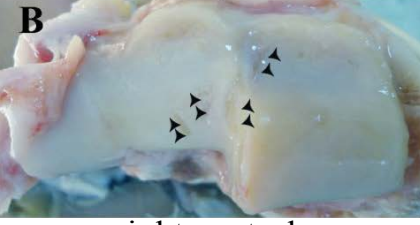

right control

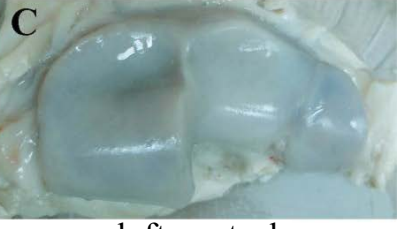

left control

Figure 5: Representative images of the gross morphology of the distal articular surface of the radius of treated and control joints. Black arrows represent the fibrous like repair tissue however, the arrowhead represent the cartilage erosions.
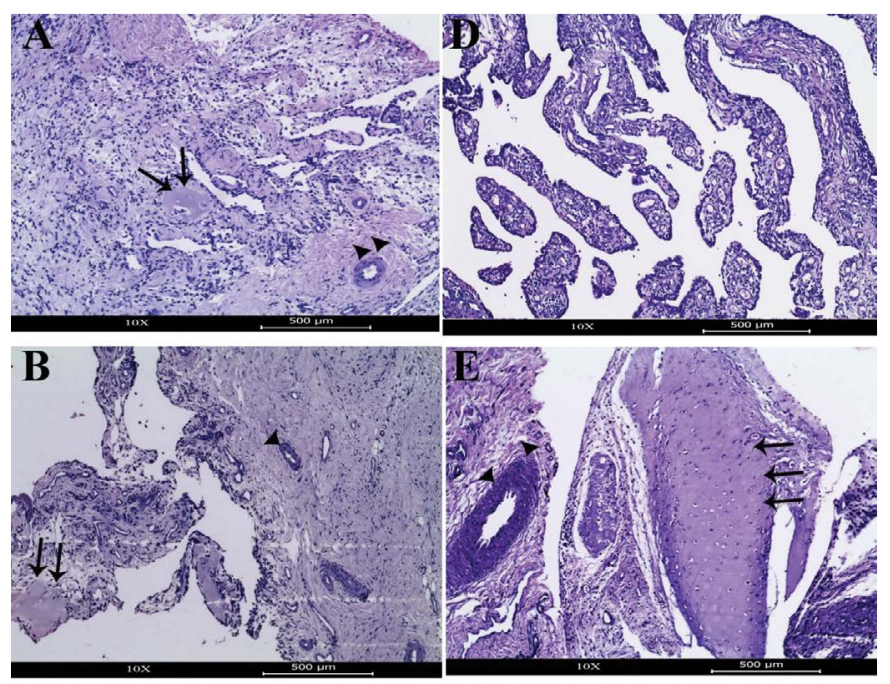

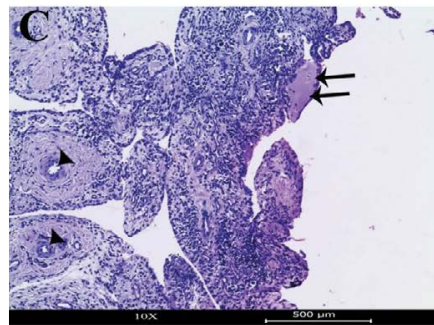

Right PPS

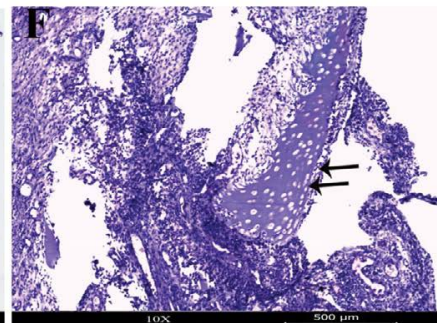

Right Control

Figure 6: Represent the light microscopy of the synovial membrane of right PPS and Control joints. Black arrow represents impeded cartilage fragments while arrowheads represent the blood vessels. A and B shows light cellular infiltration. C shows moderate cellular infiltration. However, D, E and F shows severe cellular infiltration noted specially around the cartilage fragments.

Light microscopy of synovial membrane: There was no significant difference in synovial membrane intimal hyperplasia, or subintimal edema between right and left joints of both groups $(\mathrm{P}=1.000)$.

Synovial membrane cellular infiltration was increased in right control joints $(3.33 \pm 0.47)$ (Figures $6 \mathrm{~A}-6 \mathrm{~F})$ and right PPS treated joints $(1.33 \pm 0.47)$ both groups were significantly different $(\mathrm{P}=0.003)$. The right control joints characterized by large cartilage particles embedded inside the subintimal layer surrounded by a severe zone of cellular infiltration (Figures 6E and 6F). Right PPS joints had mild zone of cellular infiltration around some cartilage particles (Figures 6A-6C).

Synovial membrane vascularity was increased in right PPS joints $(1.67 \pm 0.47)$ (Figures 6A and 6B), and right control joints $(3.50 \pm 0.50)$ (Figure 6E) compared to left control joints $(\mathrm{P}<0.001)$. Right PPS and control joint were statistically different $(\mathrm{P}=0.012)$.

Subintimal fibrosis was increased in right PPS joints $(1.33 \pm 0.47)$
(Figure 6A) and right control joints $(2.33 \pm 0.47)$ (Figure 6D). Right PPS and control joints were statistically different $(\mathrm{P}=0.014)$.

Light microscopy of articular cartilage: Histologic evaluation of sample $\mathrm{C} 1$ and $\mathrm{C} 3$ via $\mathrm{H} \& \mathrm{E}$ revealed a significant difference in $\mathrm{OA}$ score for the right control joints compared to its left normal control joints (Figures 7A-7F) $(\mathrm{P}<0.002)$. $\mathrm{C} 1$ histologic score revealed the same damage as $\mathrm{C} 3$. In the right control joints, the lesion (C1 and C3:5.67 \pm 0.47), was characterized by denudation, complete erosion of hyaline cartilage to level of subchondral bone accompanied by granulation tissue (Figure 7E). Some samples had changes in the contour of the articular surface characterized by microfractures (Figure $7 \mathrm{~F}$ ), deep layer cyst formation (Figure $7 \mathrm{~B}$ ) and reparative granulation tissue (Figure 7D) or fibrocartilage (Figure 7A) focally above the level of the eroded and denuded articular surface. In right PPS joints (C1 $1.5 \pm 0.50$ and C3:2.0 \pm 0 ), defects had a well-developed layer of typical articular cartilage containing chondrocytes in the deep and middle zone however 


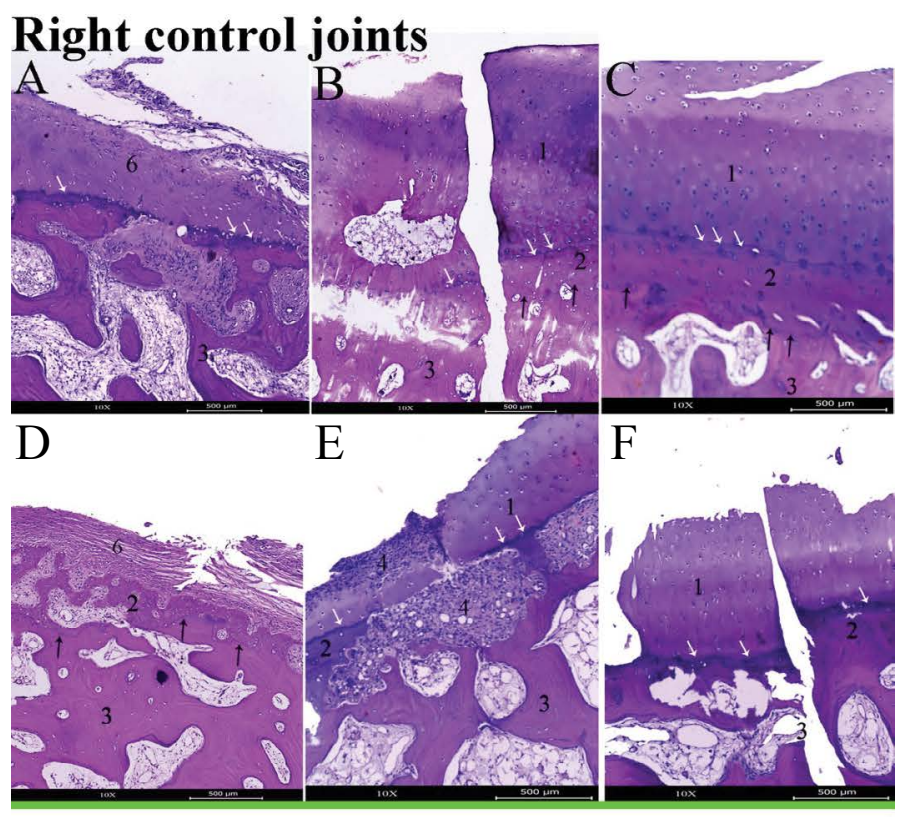

\section{Right PPS joints}

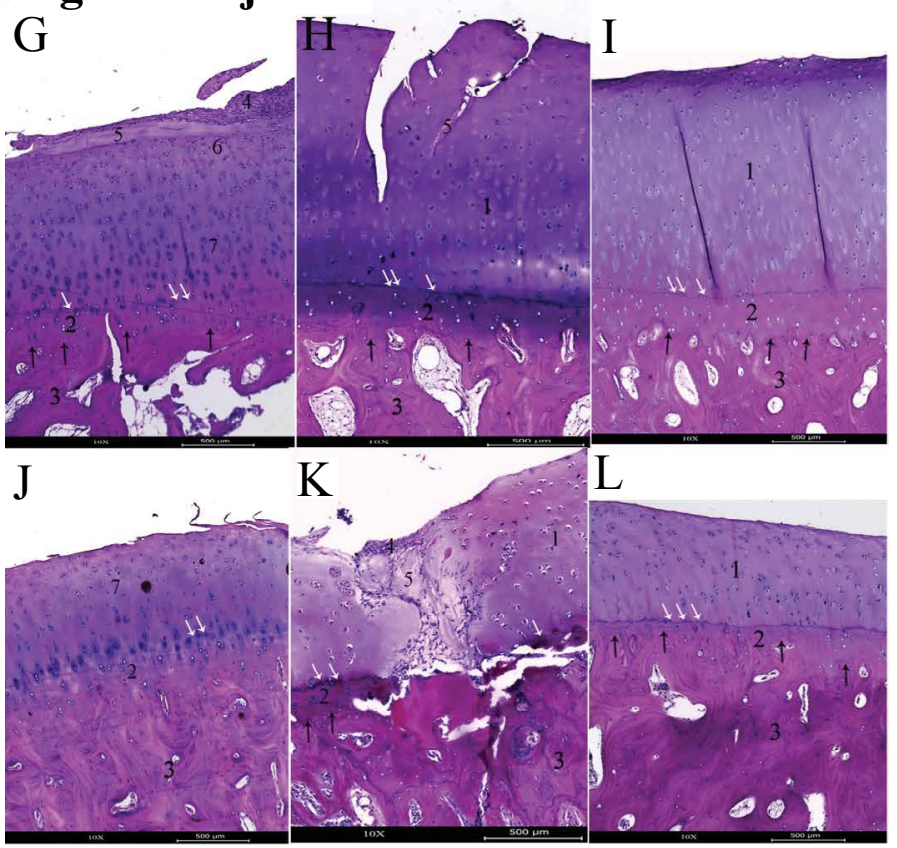

Figure 7: Representative images from light microscopy of the articular cartilage of right control joints (A-F) and right PPS joints (G-L), white arrows represents the tidemark, black arrows represents the cement line, (1) old cartilage, (2) calcified cartilage, (3) subchondral bone, (4) granulation tissue, (5) collagen-like, (6) fibrocartilage (7) hyaline-like tissue.

the superficial zone contained more fibrous layer of the flattened fibrocartilaginous cells. Chondrocytes deep within the cartilage layer had continued to undergo the typical sequence of differentiation (Figures 7G-7J). There was evidence of replacement of the dead chondrocytes and resorption and reconstitution of the extracellular matrix within the repair tissue (Figures $7 \mathrm{~K}$ and $7 \mathrm{~L}$ ). Sections with partial defects (vertical fissures) had no healing evidence in control group (Figure 7C) however in PPS group; there was an evidence of minimal extra cellular hyaline-like matrix developed between fissures (Figure $7 \mathrm{H}$ ). The right joint was significantly different in histological score between PPS and control groups $(\mathrm{P}=0.003)$.
Scanning electron microscopy of the synovial membrane: The synovial membrane of right joints revealed changes in both PPS $(2 \pm 0)$ and control group $(4 \pm 0)$. However control group was characterized by loss of synovial villi, deposition of cartilage fragments and formation of cuboidal crystals adhering to the synovial membrane (Figure 8A). Right PPS joints shows mild changes includes fibrosis but with presence of synovial villi in some regions (Figure $8 \mathrm{~B}$ ). There were significant differences in synovial villi destruction between the both groups $(\mathrm{P}=0.001)$.

Scanning electron microscopy of the cartilage surface: C2 in 
Citation: Elmesiry AM, Seleim MA, Mansour AA, Hill DC (2016) Pentosan Polysulfate as a Disease Modifier of Cartilage Degeneration in Experimental Osteoarthritis. J Arthritis 5: 199. doi:10.4172/2167-7921.1000199
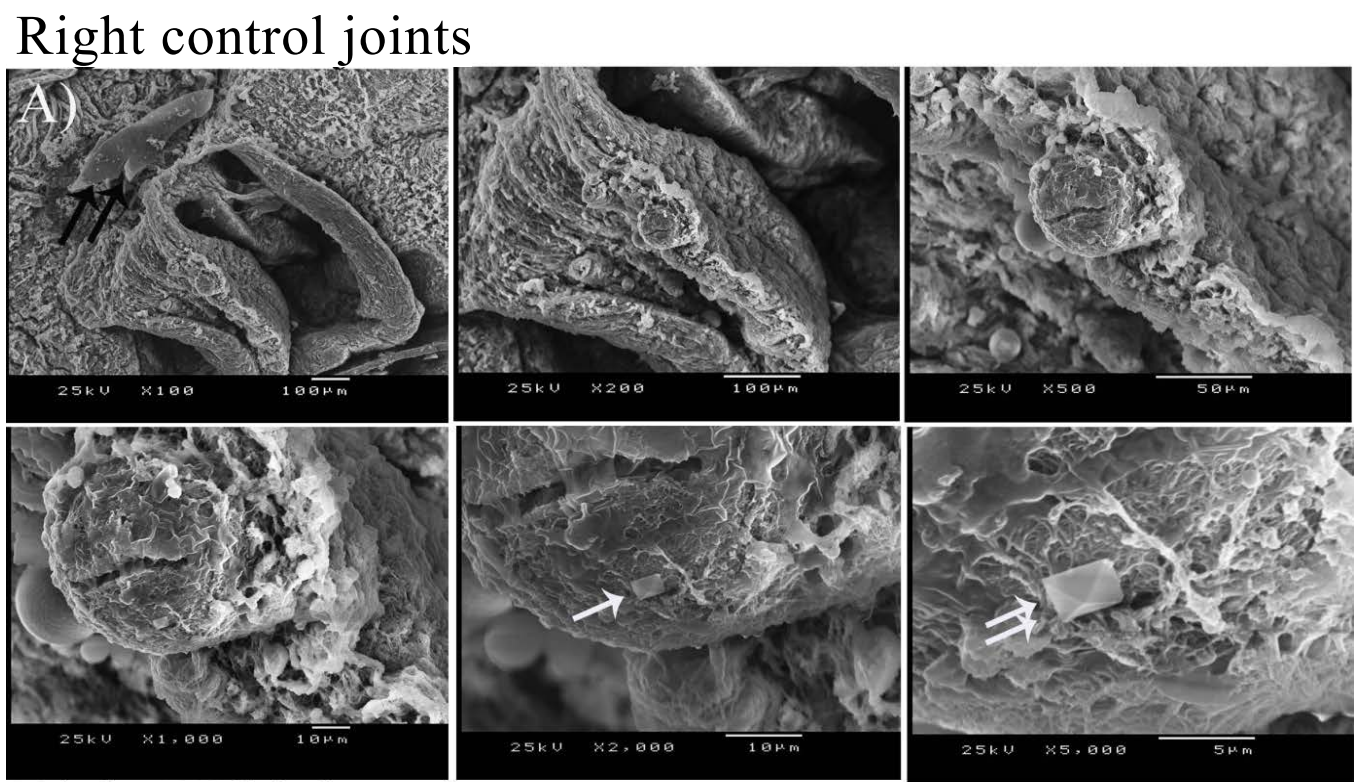

\section{Right PPS joints}
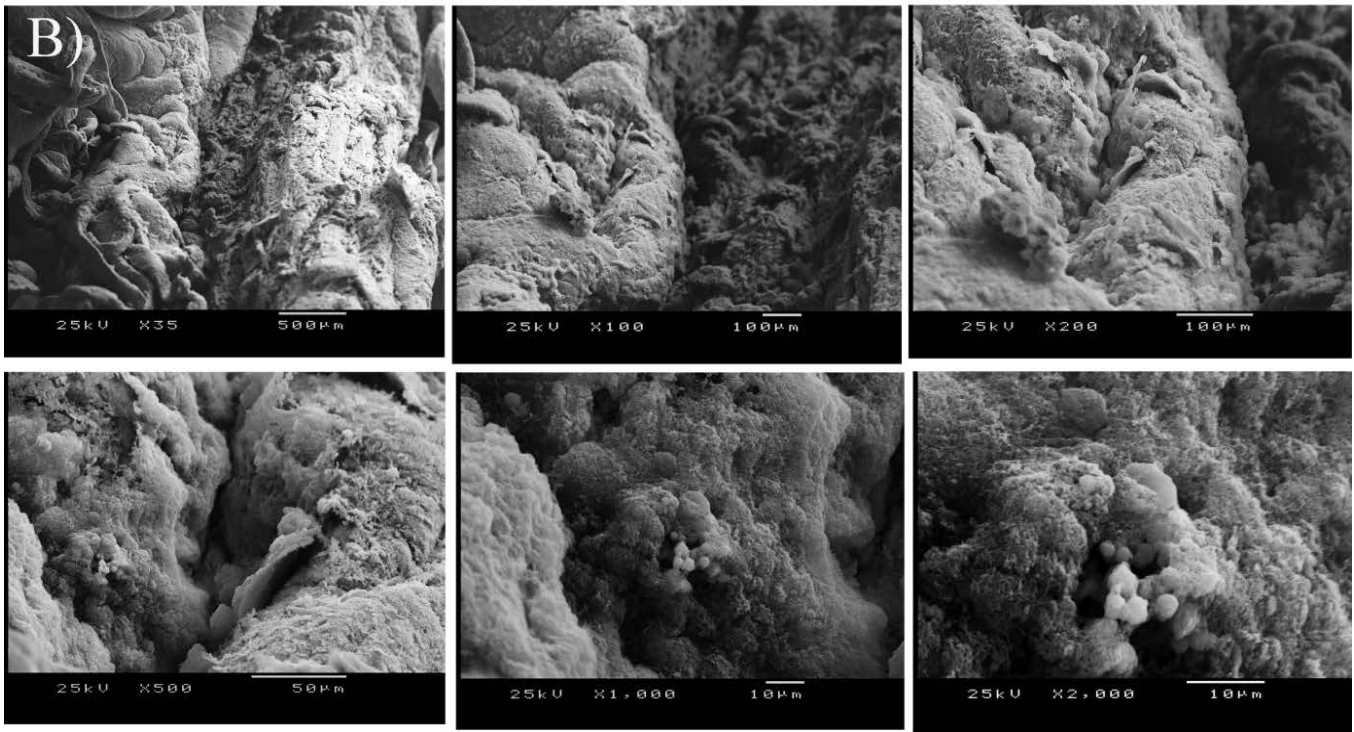

Figure 8: Representative images of the SEM of synovial membrane of right control joints (A) and right PPS joints (B). Black arrows represent the cartilage fragments and white arrows represent the crystals.

right control joints had partial and full thickness cartilage fissures passed through the articular surface and penetrated deeply into the radial zone and sometimes to the level of the subchondral bone $(4 \pm 0)$ (Figures 9A-9C). However in right PPS treated joints these defects were fully filled with repair tissue $(1 \pm 0)$ (Figure 9D). This repair tissue was rough and acellular however in some areas, evidence of chondrocytes is revealed by the occurrence of pits. There was a significant difference between PPS and control right joints $(\mathrm{P}=0.001)$. $\mathrm{C} 4$ in right control joints revealed the same damage as $\mathrm{C} 2$ (Figures $9 \mathrm{~B}$ and $9 \mathrm{C}$ ). However in right PPS-treated joints $(2 \pm 0)$ large (Figure 9E) and small fissures (Figure 9F) were partially filled with repair tissue and the remaining lesions were limited to partial thickness fissures in some locations.

\section{Discussion}

In the present study, injection of allogenous cartilage particles
(ACP) effectively resulted in clinical, gross, and histologic changes indicative of osteoarthritis. The lesions characterized by both chronic synovitis and osteoarthritis that includes partial and full-thickness cartilage erosion. During this study, no adverse effects were recorded and a mild degree of lameness was induced.

Clinically, NaPPS has been used to treat horses with mild or earlystage osteoarthritis, particularly with multiple joint involvements, because it is a systemic treatment rather than an intra-articular one. The ACP model used in the present study creates marked osteoarthritis and should be ideal to evaluate the efficacy of NaPPS.

In the present study, the dosage administered $(3 \mathrm{mg} / \mathrm{kg}$, once weekly for 4 weeks) was effective and elicit a therapeutic response without adverse effects in all clinical variables in this model. This is in contrast to another study [19] in which the author mentioned that 


\section{Right Control joints}

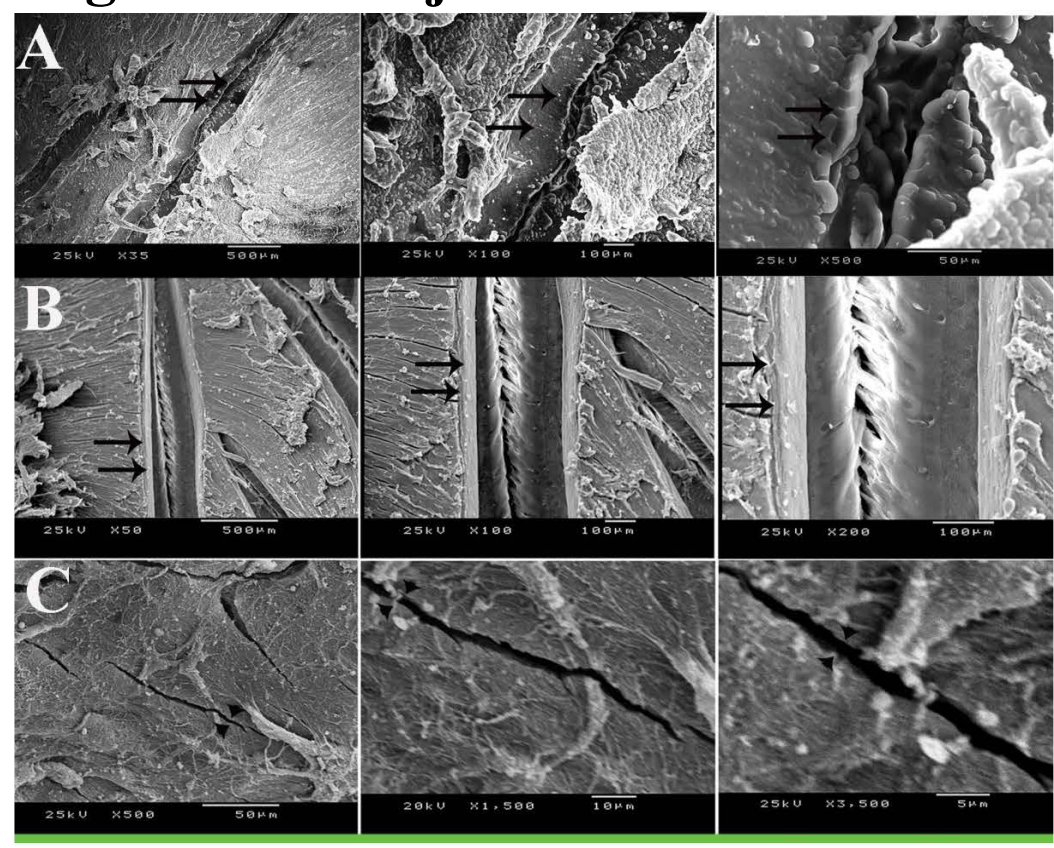

\section{Right PPS joints}

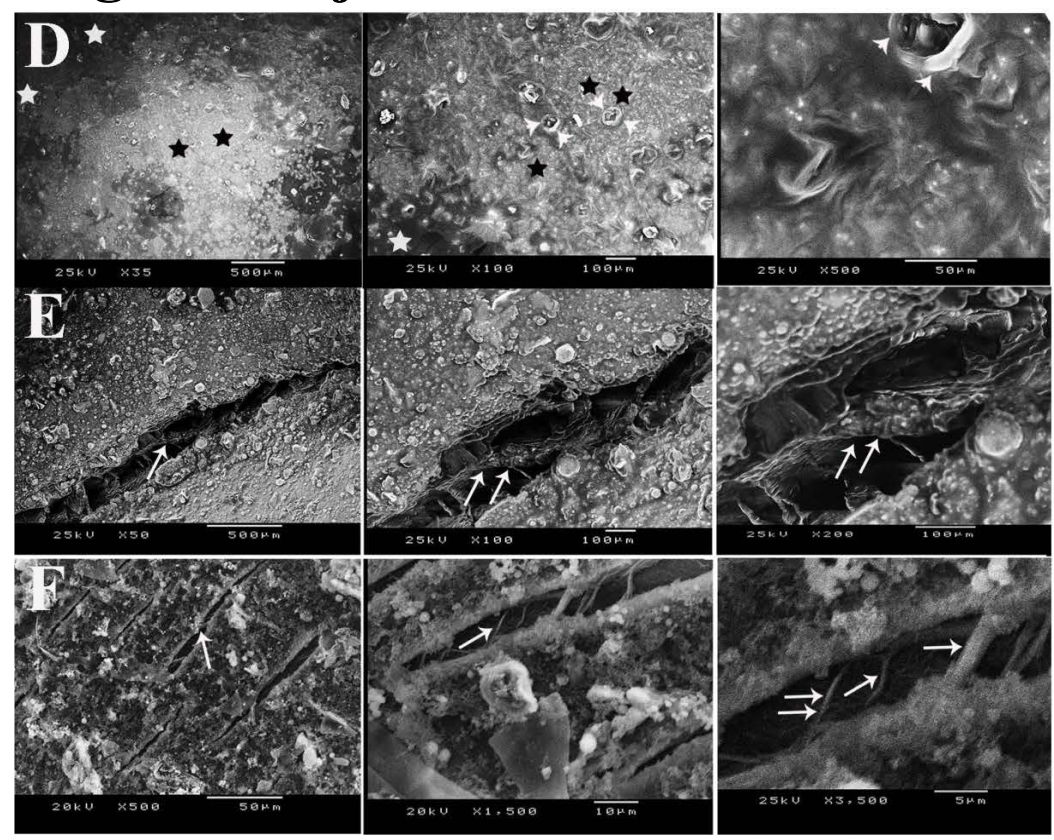

Figure 9: Representative Series of magnified images of the articular cartilage SEM for right control joints (A-C) and right PPS joints (D-F), Black arrows refers to the large macro cracks, black arrow heads refers to the micro cracks, white arrows refers to new filament formation, black stars refers to new repair tissue, white arrow heads refers to pits with underlying chondrocyte and white stars refers to old cartilage.

the same dose was too low to elicit a therapeutic response but this difference may be due to the nature of the experimental animal model.

Improvement in the synovial membrane histological score and reduction of cartilage fragments size in PPS treated joints indicates that PPS enhances the phagocytic activities of the mononuclear leukocytes to engulf the foreign bodies. Furthermore, reduction in synovial membrane vascularity confined to the anti-angiogenesis effect of PPS.
Deposition of CPPD or BCP synovial crystals in osteoarthritis are common in human [31] and equines [32] clinical cases. This crystal is a consequence of rising of $\mathrm{Ca}, \mathrm{P}$ and $\mathrm{Mg}$ [33-35] ions however, the mechanism of its formation is still under investigation.

Rising of the $\mathrm{Ca}, \mathrm{Mg}$ and $\mathrm{P}$ ions are consequently a reason of broken tidemark and exposure of the subchondral bone [24].

Formation of large russet shape crystals was a feature of the ACP 
model [24] however in the present study formation of small cuboidal crystals in the control group. This difference may be due to decrease of the Ca concentration on the synovial fluid after cessation of ACP injection.

The cuboidal crystals are formed due to rising of $\mathrm{P}$ and $\mathrm{Mg}$ concentration on the control group however it is not found on the PPS group due to lowering of its concentration with PPS treatment.

PPS decrease crystals formation through repairing of the broken tide mark and enhancing the healing of the cartilage upper layer. This leads to dissolution of the crystals and diffuse out of the $\mathrm{Ca}, \mathrm{P}$ and $\mathrm{mg}$.

Using Pritzker grading system was suitable for evaluating the osteoarthritic joints however; in the evaluation of the healing stage, it may need some addition of healing features to grade 1, 2, 3 and 4 .

This study confirms the previous reports on repair of articular cartilage in the horses. Among these studies, it is generally accepted that articular cartilage has limited reparative powers [36,37].

Neochondrogenesis can be stimulated by PPS as healing of fullthickness cartilage defects benefits from the production of granulation issue by subchondral mesenchymal cells. This tissue matures with time and undergoes metaplasia to fibrocartilage, or hyaline-like cartilage [36].

Convalescence time has been the subject of considerable debate. Granulation tissue was reported to fill the defects in one month [38], however maturation to fibrocartilage varies from 6 weeks [39], 3 month [40] and four month [38,41,42]. Development of the hyaline like cartilage is also varies from 8 weeks [39], 4 month [43], 6 month [38], 12 month [41,44] and 15 month [42].

This study reported that at 56-day post treatment, control joints with full thickness cartilage defects were filled with fibrocartilage. However the PPS treated joints were filled with hyaline-like tissue and chondroblasts attached to the subchondral bone and fibrous-like tissue superficially. Complete healing was not achieved in any treatment group.

Variation on healing stage in individual animals or regions in the same region influenced by influenced by a number of factors including the thickness, size, and anatomical location of the defect [36]. Posttraumatic and postoperative management of joint injuries varies considerably and is poorly understood. However, the degree of weightbearing allowed and the length of convalescence can affect the quality of the reparative tissue [36,37].

In the present study, defects of healing confined to some zones may be due to presence of the old calcified cartilage layer, which may interfere with the attachment of the repair tissue to the subchondral bone [44].

This study confirm the previous morphological studies documented the inability of superficial or partial-thickness cartilaginous defects to undergo repair. Since the inflammatory response is absent, repair is limited to intrinsic healing which has limited potential for complete repair [36].

Previous report studying healing of superficial cartilage defects with SEM reported no healing 6-month post defect creation [45]. However, long term study (18 months) reported homogeneous material with a pitted-like appearance on the floor of the defects somewhat similar to that of surrounding cartilage but the surface of the defect was invariably quite rough and irregular [46]. Our study is the first to examine the healing of partial and full thickness cartilage defects. Examination of the articular cartilage with SEM was able to detect improvement in PPS joints. Disappearance of cartilage erosion in PPS treated joints and the appearance of a pitted surface suggests that a newly layer of matrix is largely formed. It is interesting to note that as long as an acellular layer of matrix persists no pits are seen but when such a layer presumably disappears or becomes attenuated the presence of the underlying chondrocytes is revealed by the occurrence of pits. This is in keeping with the idea that pits as seen on the surface of normal articular cartilage are due to the presence of superficially placed chondrocytes.

PPS modulates proteolytic enzymes in vitro and protects cartilage from proteoglycan loss from the extracellular matrix. This anticatabolic effect, combined with the antithrombotic effect, may result in improved cellular nutrition and matrix homeostasis [7]. These features would be supported by the significant decrease in articular cartilage fibrillation with NAPPS treatment observed in the present study.

These data clearly demonstrate the ability of PPS to stimulate the biosynthesis of components of the extracellular matrix accompanied by limiting their degradation by its anticatabolic effects. These beneficial pharmacological activities of PPS have resulted in its widespread use for the treatment of osteoarthritis in both veterinary $[8,10,16,11,12]$, and human practice [14-16]. Moreover, the present study confirm previous works demonstrating the ability of this drug to induce chondrogenic differentiation of mesenchymal progenitor stem cell in vivo [47] and in vitro [48].

\section{Authors' Declaration of Interests}

There are no conflicts of interest.

\section{Sources of Funding}

We thank Biopharm Australia for generous financial support. The experimental work performed was not influenced at any stage by the supporting company.

\section{Author Contributions Statement}

All authors have made substantial contributions to all three of sections below:

- The conception and design of the study, acquisition of data, analysis and interpretation of data.

- Drafting the article or revising it critically for important intellectual content

- Final approval of the version to be submitted.

Ahmed M Elmesiry is the author responsible for the integrity of the work as a whole, from inception to finished article.

\section{Ethical Board Review Statement}

The experiment was approved by the Committee on Animal Experimentation at the Kafrelsheikh University, Egypt (Protocol no. VET1789 - 1/4/2013).

\section{Acknowledgments}

The authors would like to express their gratitude to Dr. Margaret Smith for her assistance in editing the manuscript. Also, many thanks for Magdi Mostafa and Yassen Qura for preparation of the light and electron microscopy specimens.

\section{References}

1. Mcllwraith CW (2005) From Arthroscopy to Gene Therapy-30 Years of Looking in Joints. Am Assoc Equine Pract 51: 65-113.

2. Jeffcott LB, Rossdale PD, Freestone J, Frank CJ, Towers-Clark PF (1982) An assessment of wastage in thoroughbred racing from conception to 4 years of age. Equine Vet J 14: 185-198.

3. Rossdale PD, Hopes R, Digby NJ, offord K (1985) Epidemiological study of wastage among racehorses 1982 and 1983. Vet Rec 116: 66-69.

4. Wilsher S, Allen WR, Wood JL (2006) Factors associated with failure of thoroughbred horses to train and race. Equine Vet J 38: 113-118. 
Citation: Elmesiry AM, Seleim MA, Mansour AA, Hill DC (2016) Pentosan Polysulfate as a Disease Modifier of Cartilage Degeneration in Experimental Osteoarthritis. J Arthritis 5: 199. doi:10.4172/2167-7921.1000199

5. Mcllwraith CW, Frisbie DD, Kawcak CE (2012) The horse as a model of naturally occurring osteoarthritis. Bone Joint Res 1: 297-309.

6. Ghosh $P$ (1999) The pathobiology of osteoarthritis and the rationale for the use of pentosan polysulfate for its treatment. Semin Arthritis Rheum 28: 211-267.

7. Mcllwraith CW (2016) Pentosan Polysulfate, in Joint Disease in the Horse (2 $2^{\text {nd }}$ edtn), WB Saunders, Edinburgh, UK.

8. Altman RD, Rogachevsky R, Dean D, Howell D (1996) Effects of pentosan polysulphate and growth factors on cartilage integrity in animal models of osteoarthritis. Osteoarthritis and Cartilage 4: ii.

9. Budsberg SC, Bergh MS, Reynolds LR, Streppa HK (2007) Evaluation of pentosan polysulfate sodium in the postoperative recovery from cranial cruciate injury in dogs: a randomized, placebo-controlled clinical trial. Vet Surg 36: 234 244

10. Innes JF, Barr AR, Sharif M (2000) Efficacy of oral calcium pentosan polysulphate for the treatment of osteoarthritis of the canine stifle joint secondary to cranial cruciate ligament deficiency. Vet Rec 146: 433-437.

11. Read RA, Cullis-Hill D, Jones MP (1996) Systemic use of pentosan polysulphate in the treatment of osteoarthritis. J Small Anim Pract 37: 108-114.

12. Rogachefsky RA, Dean DD, Howell DS, Altman RD (1993) Treatment of canine osteoarthritis with insulin-like growth factor-1 (IGF-1) and sodium pentosan polysulfate. Osteoarthritis Cartilage 1: 105-114

13. Ghosh P, Armstrong S, Read R, Numata Y, Smith S, et al. (1993) Animal models of early osteoarthritis: their use for the evaluation of potential chondroprotective agents. Agents Actions Suppl 39: 195-206.

14. Faaij RA, Srivastava N, van Griensven JM, Schoemaker RC, Kluft C, et al. (1999) The oral bioavailability of pentosan polysulphate sodium in healthy volunteers. Eur J Clin Pharmacol 54: 929-935.

15. Ghosh P, Edelman J, March L, Smith M (2005) Effects of pentosan polysulfate in osteoarthritis of the knee: A randomized, double-blind, placebo-controlled pilot study. Current Therapeutic Research 66: 552-571.

16. Kumagai K, Shirabe S, Miyata N, Murata M, Yamauchi A, et al. (2010) Sodium pentosan polysulfate resulted in cartilage improvement in knee osteoarthritis-an open clinical trial. BMC Clin Pharmacol 10: 7 .

17. Dart A, Perkins N, Dowling, Batterham T, Livingston C, et al. (2001) The effect of three different doses of sodium pentosan polysulphate on haematological and haemostatic variables in adult horses. Aust Vet J 79: 624-627.

18. Fuller CJ, Ghosh P, Barr AR (2002) Plasma and synovial fluid concentrations of calcium pentosan polysulphate achieved in the horse following intramuscular injection. Equine Vet J 34: 61-64.

19. Mcllwraith CW, Frisbie DD, Kawcak CE (2012) Evaluation of intramuscularly administered sodium pentosan polysulfate for treatment of experimentally induced osteoarthritis in horses. Am J Vet Res 73: 628-633.

20. Chrisman OD, Fessel JM, Southwick WO (1965) Experimental production of synovitis and marginal articular exostoses in the knee joints of dogs. Yale $J$ Biol Med 37: 409-412.

21. Evans CH, Mazzocchi RA, Nelson DD, Rubash HE (1984) Experimenta arthritis induced by intraarticular injection of allogenic cartilaginous particles into rabbit knees. Arthritis Rheum 27: 200-207.

22. Hurtig MB (1988) Use of autogenous cartilage particles to create a model of naturally occurring degenerative joint disease in the horse. Equine Vet J Supp 20: $19-22$.

23. Elmesiry A, Seleim M, Cullis-Hill D (2014) lodoacetate and allogenous cartilage particles as models for arthritis induction in equine. International Journal of Veterinary Science and Medicine 2: 142-150.

24. Elmesiry A, Seleim M, Cullis-Hill D (2016) In vivo Model of Crystal-Associated Osteoarthritis. Global Veterinaria 16: 285-297.

25. Baxster GM, Stashak TS (2011) Examination for Lameness, in Adams and Stashak's Lameness in Horses. Wiley, USA

26. Toutain PL, Cester CC (2004) Pharmacokinetic-pharmacodynamic relationships and dose response to meloxicam in horses with induced arthritis in the right carpal joint. Am J Vet Res 65: 1533-1541.

27. Steel CM (2008) Equine synovial fluid analysis. Vet Clin North Am Equine Pract 24: $437-454$
28. Mcllwraith CW, Frisbie DD, Kawcak CE, Fuller CJ, Hurtig M, et al. (2010) The OARSI histopathology initiative - recommendations for histological assessments of osteoarthritis in the horse. Osteoarthritis Cartilage 18: S93-S105.

29. Pritzker KP, Gay S, Jimenez SA, Ostergaard K, Pelletier JP, et al. (2006) Osteoarthritis cartilage histopathology: grading and staging. Osteoarthritis cartilage 14: 13-29.

30. Clark JM, Simonian PT (1997) Scanning electron microscopy of "fibrillated" and "malacic" human articular cartilage: technical considerations. Microsc Res Tech 37: 299-313.

31. Rosenthal AK (2006) Calcium crystal deposition and osteoarthritis. Rheum Dis Clin North Am 32: 401-412, vii.

32. Hayes A, Swan AJ, Dieppe PA (1994) Crystals in equine articular cartilage. Res Vet Sci 57: 106-109.

33. Lagier R, Baud CA (2003) Magnesium whitlockite, a calcium phosphate crystal of special interest in pathology. Pathol Res Pract 199: 329-335.

34. Scotchford CA, Ali SY (1995) Magnesium whitlockite deposition in articular cartilage: a study of 80 specimens from 70 patients. Ann Rheum Dis 54: 339 344.

35. Scotchford CA, Vickers M, Ali SY (1995) The isolation and characterization of magnesium whitlockite crystals from human articular cartilage. Osteoarthritis Cartilage 3: 79-94

36. Desjardins MR, Hurtig MB (1990) Cartilage healing: A review with emphasis on the equine model. Can Vet J 31: 565-572.

37. Mcllwraith CW, Frisbie DD (2010) Microfracture: Basic Science Studies in the Horse. Cartilage 1: 87-95.

38. Riddle WE Jr (1970) Healing of articular cartilage in the horse. J Am Vet Med Assoc 157: 1471-1479.

39. Frisbie DD, Oxford JT, Southwood L, Trotter GW, Rodkey WG, et al. (2003) Early events in cartilage repair after subchondral bone microfracture. Clin Orthop Relat Res pp: 215-227.

40. Convery FR, Akeson WH, Keown GH (1972) The repair of large osteochondral defects. An experimental study in horses. Clin Orthop Relat Res 82: 253-262.

41. Frisbie DD, Trotter GW, Powers BE, Rodkey WG, Steadman JR, et al. (1999) Arthroscopic Subchondral Bone Plate Microfracture Technique Augments Healing of Large Chondral Defects in the Radial Carpal Bone and Medial Femoral Condyle of Horses. Veterinary Surgery 28: 242-255

42. Grant BD (1975) Repair mechanisms of osteochondral defects in Equidae: a comparative study of untreated and X-irradiated defects. Proceedings of the annual convention of the American Association of Equine Practitioners.

43. Morisset S, Frisbie DD, Robbins PD, Nixon AJ, Mcllwraith CW (2007) IL-1ra/ IGF-1 gene therapy modulates repair of microfractured chondral defects. Clin Orthop Relat Res 462: 221-228.

44. Frisbie DD, Morisset S, Ho CP, Rodkey WG, Steadman JR, et al. (2006) Effects of calcified cartilage on healing of chondral defects treated with microfracture in horses. Am J Sports Med 34: 1824-1831.

45. Ghadially FN, Ailsby RL, Oryschak AF (1974) Scanning electron microscopy of superficial defects in articular cartilage. Ann Rheum Dis 33: 327-332.

46. Ghadially FN, Thomas I, Oryschak AF, Lalonde JM (1977) Long-term results of superficial defects in articular cartilage: a scanning electron-microscope study. J Pathol 121: 213-217.

47. Goldschlager T, Ghosh P, Zannettino A, Gronthos S, Rosenfeld JV, et al (2010) Cervical motion preservation using mesenchymal progenitor cells and pentosan polysulfate, a novel chondrogenic agent: preliminary study in an ovine model. Neurosurg Focus 28: E4.

48. Ghosh P, Wu J, Shimmon S, Zannettino AC, Gronthos S, et al. (2010) Pentosan polysulfate promotes proliferation and chondrogenic differentiation of adult human bone marrow-derived mesenchymal precursor cells. Arthritis Res Ther 12: R28. 